\title{
A Pancreatic Cyst Leading to Obstructive Jaundice
}

\author{
Catarina Sousa Félix ${ }^{a}$ Susana Chaves Marques ${ }^{b}$ Miguel Bispo $^{b}$ \\ Mireia Castilloc Tiago Bana e Costa ${ }^{a}$ Cristina Chagas $^{a}$ \\ a Gastroenterology Department, Centro Hospitalar Lisboa Ocidental, Lisbon, Portugal; \\ ${ }^{\mathrm{b}}$ Gastroenterology Department, Champalimaud Foundation, Lisbon, Portugal; \\ 'Pathology Department, Champalimaud Foundation, Lisbon, Portugal
}

\section{Keywords}

Pancreas · Pancreatic cyst · Pancreatic neoplasm .

Endoscopic ultrasound-guided fine-needle aspiration

\section{Icterícia obstrutiva associada a quisto pancreático}

\section{Palavras Chave}

Pâncreas · Quisto pancreático · Neoplasia pancreática . Aspiração por agulha fina guiada por ultrassonografia endoscópica

A 71-year-old female patient presented with new-onset jaundice (total bilirubin $7.39 \mathrm{mg} / \mathrm{dL}$, conjugated bilirubin $5.38 \mathrm{mg} / \mathrm{dL}$ ), choluria, and acholia. Her past medical history was remarkable for a pancreatic head cystic lesion diagnosed in 2009; it was a 24-mm multilocular cystic lesion, with no communication with the pancreatic duct or dilatation of this duct, with a central scar that remained asymptomatic and stable in size until 2015, when follow-up was lost. An abdominal ultrasound revealed a $47 \times 45 \mathrm{~mm}$ heterogeneous mass in the pancreatic head, associated with de novo common bile duct (CBD) dilatation (17 $\mathrm{mm}$ in the liver hilum).

\section{KARGER}

karger@karger.com www.karger.com/pjg
(C) 2020 Sociedade Portuguesa de Gastrenterologia Published by S. Karger AG, Basel

This article is licensed under the Creative Commons AttributionNonCommercial-NoDerivatives 4.0 International License (CC BYNC-ND) (http://www.karger.com/Services/OpenAccessLicense). Usage and distribution for commercial purposes as well as any distribution of modified material requires written permission.
Magnetic resonancecholangiopancreatography showed a multilocular pancreatic head cystic lesion, measuring $60 \times 70 \times 57 \mathrm{~mm}$ and apparently communicating with the main pancreatic duct (MPD), without evident central scar. There was also CBD and intrahepatic bile duct dilation, as well as pancreatic body and tail atrophy (Fig. 1).

Endoscopic ultrasound (EUS) documented a predominantly microcystic lesion located in the head of the pancreas, measuring $53 \times 46 \mathrm{~mm}$, with a few macrocysts and pseudo-solid areas, compressing the $\mathrm{CBD}$ and the superior mesenteric vein, and without vascular invasion or Wirsung dilatation (Fig. 2). Fine-needle aspiration of the macrocyst and of a pseudo-solid area was performed. Cyst fluid biochemistry analysis revealed a high amylase level (54,085 $\mathrm{UI} / \mathrm{L}$ ) and a low CEA (2 ng/mL). EUS-fine-needle aspiration cytology showed cuboidal cells, negative for CK8/18, synaptophysin, and chromogranin-A (Fig. 3). For jaundice palliation, endoscopic retrograde cholangiopancreatography (ERCP) was then performed, and a plastic stent was placed. During ERCP, incidental pancreatic duct cannulation and contrast injection occurred, and pancreatography showed a multicystic lesion in the head of the pancreas and confirmed MPD communication (Fig. 4).

At this point, differential diagnosis include sidebranch intraductal papillary mucinous neoplasm, muci-

Catarina Sousa Félix

Gastroenterology Department, Centro Hospitalar Lisboa Ocidental

Rua da Junqueira 126

PT-1349-019 Lisbon (Portugal)

sfelixcatarina@gmail.com 


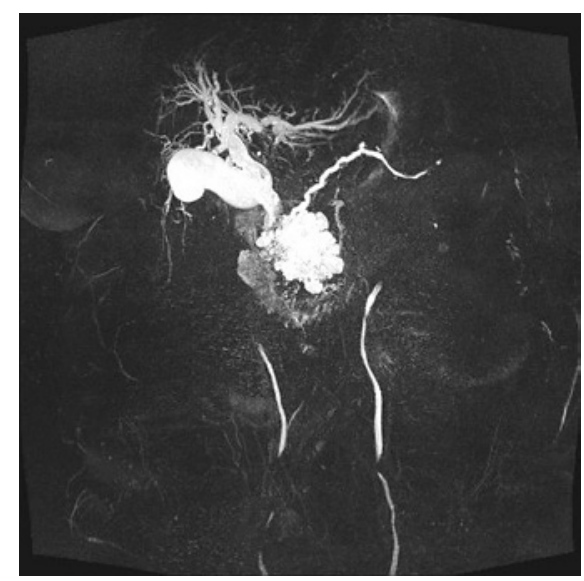

Fig. 1. Magnetic resonance cholangiopancreatography. Multilocular pancreatic head cystic lesion, apparently communicating with the MPD, and CBD and intrahepatic bile duct dilation.

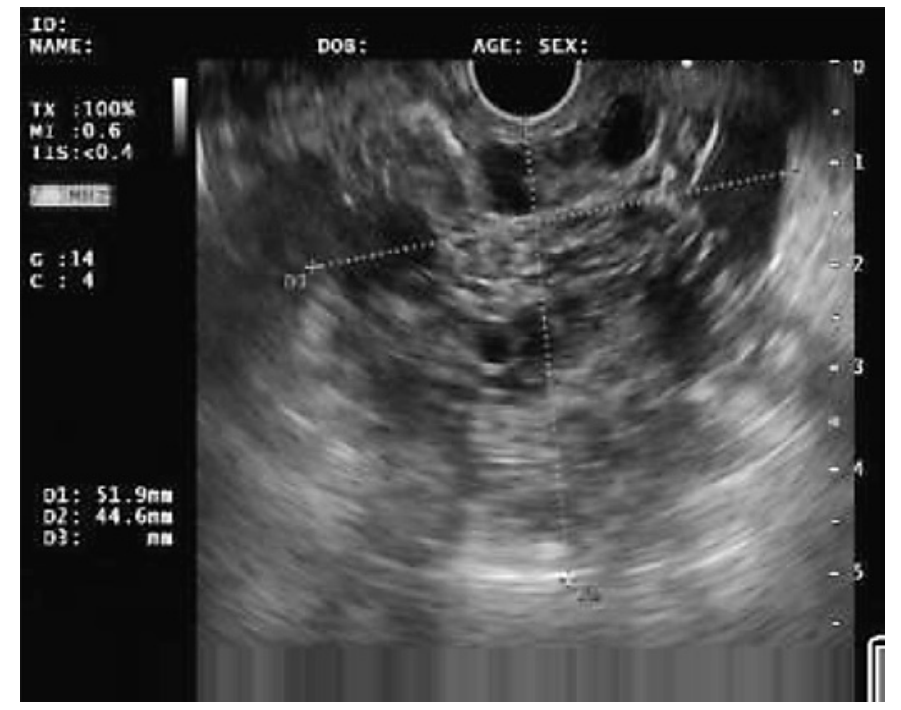

Fig. 2. EUS. Predominantly microcystic pancreatic lesion located in the head of the pancreas, with a few macrocysts and pseudosolid areas.


Fig. 3. Cytology $(\times 400)$. Cuboidal cells, negative for CK8/18, synaptophysin, and chromogranin-A.

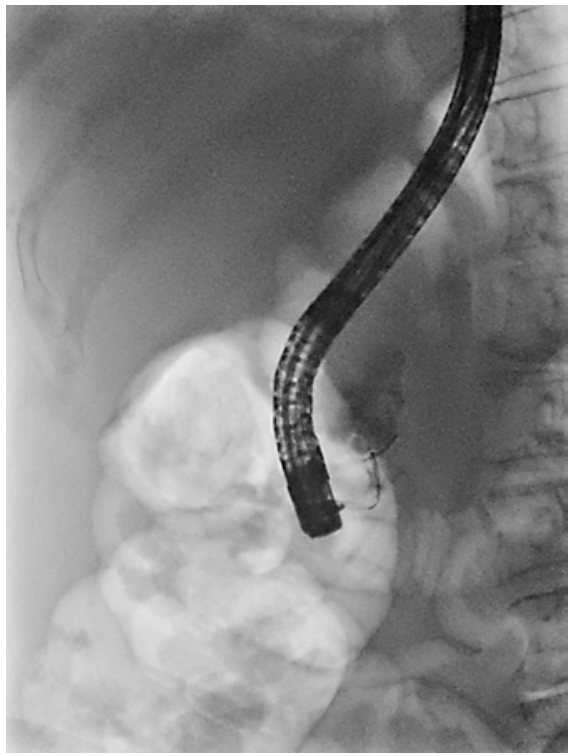

Fig. 4. ERCP (pancreatography). Multicystic pancreatic head lesion with MPD communication. nous cystic neoplasm, serous cystic neoplasm and pseudopapillary neoplasm. The previously reported scar, the low CEA, and the presence of cuboid epithelium pointed to a serous cystic neoplasm. Despite the uncertain diag- nosis, the presence of high-risk stigmata lead to surgical resection (Whipple procedure), confirming the diagnosis of a serous cystic neoplasm. After the surgery, complete resolution of the symptomatology was noted. 
Serous cystic neoplasms account for $8-17 \%$ of the clinically encountered pancreatic cystic lesions and are predominantly found in middle-aged females [1]. These lesions are usually benign and asymptomatic and present a benign clinical course in the vast majority of patients [2]. Symptoms may occur, typically in those patients with lesions $>4 \mathrm{~cm}$ in size, and are often attributed to mass effect or to infiltration of adjacent structures. Abdominal pain (25\%), palpable mass (10\%), and jaundice $(7 \%)$ are the main clinical manifestations. In such cases, symptomatic surgical resection should be considered, and once resected, no further surveillance imaging is needed [3].

In the reported case, presurgical diagnosis was not straightforward, mainly due to the presence of pseudosolid areas and cystic communication with the MPD with subsequent high amylase, which is a rare feature of serous cystic neoplasm. Although rare, communication with the MPD has been reported occasionally $(0-0.6 \%)$ in serous cystic neoplasm, requiring a strong suspicion, so that the misdiagnosis of an intraductal papillary mucinous neoplasm is avoided [1].

\section{Statement of Ethics}

Informed consent was obtained from the patient for the case publication.

\section{Disclosure Statement}

The authors have no conflicts of interest to declare.

\section{Funding Sources}

The authors have no funding sources to declare.

\section{Author Contributions}

Catarina Sousa Félix collected the data and wrote the manuscript; Susana Chaves Marques, Miguel Bispo, Mireia Castillo, Tiago Bana e Costa, and Cristina Chagas revised the manuscript and approved the final version.

\section{References}

1 Matsubayashi H, Oka Y, Ito T, Uesaka K, Sasaki K, Ono H. A Case of Serous Cystadenoma Communicating with a Stenotic Santorini's Duct and a Dilated Main Pancreatic Duct. J Gastrointestin Liver Dis. 2016 Dec;25(4): 551-4.

2 Amico EC, Alves JR, de Araújo Lima Liguori A, Sousa RL. Serous Pancreatic Cystadenoma with Compression of Wirsung's Duct. J Gastrointest Surg. 2019 Jan;23(1):176-8.

3 Zhang XP, Yu ZX, Zhao YP, Dai MH. Current perspectives on pancreatic serous cystic neoplasms: Diagnosis, management and beyond. World J Gastrointest Surg. 2016 Mar;8(3): 202-11. 